
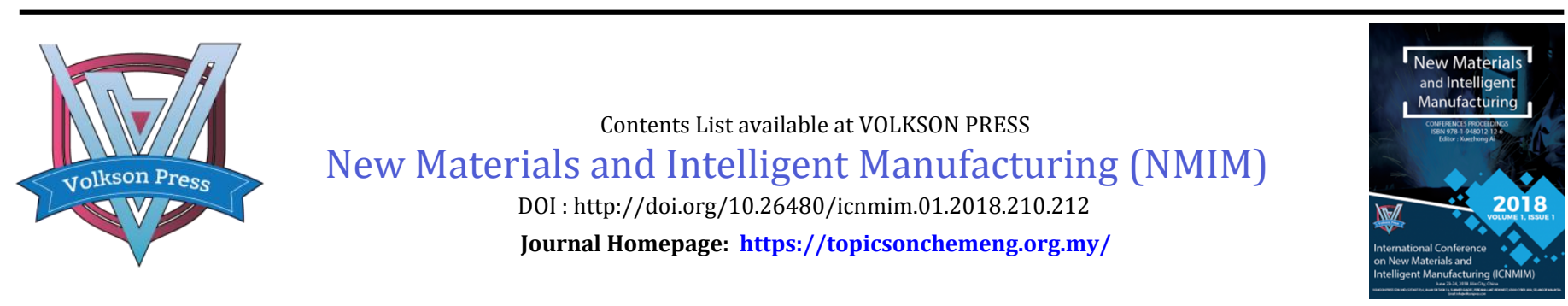

ISBN: 978-1-948012-12-6

\title{
ELECTROCHROMIC NANOCOMPOSITE FILM BASED ON MONOLACUNARY DAWSON-TYPE POLYOXOMETALATE AND $\mathrm{TIO}_{2}$ NANOWIRES
}

\author{
Chao Ma, Xiao Shu Qu*, Qing Lin Gong, Shu Ping Liu, Yan Yan Yang, Xiao Yang Yu
}

JiLin Institute of Chemical Technology, JiLin City, 132073, P. R. China.

*Corresponding Author Email: xiaoshuqu@sina.com

This is an open access article distributed under the Creative Commons Attribution License, which permits unrestricted use, distribution, and reproduction in any medium, provided the original work is properly cited

\section{ARTICLE DETAILS}

\section{Article History:}

Received 26 June 2018 Accepted 2 July 2018

Available online 1 August 2018

\section{ABSTRACT}

Electrochromic (EC) nanocomposite films consisting of monolacunary Dawson-type polyoxometalates (POMs) $\mathrm{K}_{10} \mathrm{P}_{2} \mathrm{~W}_{17} \mathrm{O}_{61}\left(\mathrm{P}_{2} \mathrm{~W}_{17}\right)$ and $\mathrm{TiO}_{2}$ nanowires $\left(\mathrm{TiO}_{2} \mathrm{NW}\right)$ were fabricated by combining hydrothermal and sol-gel spin coating assembly methods. The surface morphology and the homogeneity of the nanocomposite films were characterized by Scanning Electron Microscope (SEM). The electrochemical and electrochromic (EC) performances were examined by UV-vis spectra and chronoamperometric (CA) measurements. Compared with individual $\mathrm{P}_{2} \mathrm{~W}_{17}$ and $\mathrm{TiO}_{2} \mathrm{NW}$ structures, the nanocomposite film exhibits improved EC properties with suitable optical contrast $(15.69 \%$ at $650 \mathrm{~nm})$ and fast switching times (2.98 s and $0.82 \mathrm{~s})$.

\section{KEYWORDS}

Polyoxometalates, Electrochromic, Nanocomposite, $\mathrm{TiO}_{2}$ nanowires, Sol-gel.

\section{INTRODUCTION}

Electrochromic (EC) materials refer to a phenomenon that the transmittance, absorbance or external coloration of a material can be changed during electrochemical oxidation and reduction by an applied potential $[1,2]$. Polyoxometalates (POMs) are widely studied as a kind of EC materials over the past few years owing to their unique structures and diverse properties such as reversible oxidation and reduction properties and electrochromism [3-5]. And several new composite films based on POMs such as $\mathrm{K}_{6} \mathrm{P}_{2} \mathrm{~W}_{18} \mathrm{O}_{62}, \quad \mathrm{~K}_{10} \mathrm{P}_{2} \mathrm{~W}_{17} \mathrm{O}_{61}, \quad \mathrm{Na}_{12} \mathrm{P}_{2} \mathrm{~W}_{15} \mathrm{O}_{56}$, $\mathrm{K}_{12.5} \mathrm{Na}_{1.5}\left[\mathrm{NaP}_{5} \mathrm{~W}_{30} \mathrm{O}_{110}\right], \quad\left(\mathrm{NH}_{4}\right)_{14}\left[\mathrm{NaP}_{5} \mathrm{~W}_{30} \mathrm{O}_{110}\right], \mathrm{K}_{17} \mathrm{Ce}\left(\mathrm{P}_{2} \mathrm{~W}_{17} \mathrm{O}_{61}\right)_{2}$ were synthesized recent years, which showed suitable EC properties, suggesting that POMs can be an excellent material for the application of EC materials [6-11].

Titanium dioxide $\left(\mathrm{TiO}_{2}\right)$ has been diffusely employed as a cathodic EC and electro-active material due to its high chemical stability, low cost and electromic properties $[12,13]$. Recently, there are several reports about composite materials which were fabricated by $\mathrm{TiO}_{2}$. For example, ReyesGil et al. prepared a composite $\mathrm{TiO}_{2} / \mathrm{WO}_{3}$ film using $\mathrm{TiO}_{2}$ nanowires as an auxiliary material, which showed enhanced electrochromic performance [14]. Our laboratory reported a nanocomposite film constructed by $\mathrm{P}_{2} \mathrm{~W}_{18}$ and $\mathrm{TiO}_{2}$ nanowires, which exhibited improved EC properties and displayed potential application in EC device [15].

In these literatures, most films were prepared by the layer-by-layer (LBL) self-assembly method. It can be an important and effective method to composite the films by LBL, but there are still some drawbacks in this method. For example, this method is rather cumbersome and not conducive to industrialization $[16,17]$. Therefore, in order to promote the application of POMs-based EC devices, it seems to be a challenge to investigate a better way favorable to industrialization.

In this paper, we choose monolacunary Dawson-type $\mathrm{POMs} \mathrm{K}_{10} \mathrm{P}_{2} \mathrm{~W}_{17} \mathrm{O}_{61}$ $\left(\mathrm{P}_{2} \mathrm{~W}_{17}\right)$, whose optical contrast was the highest among POMs-based EC films, and $\mathrm{TiO}_{2}$ nanowires to fabricate a new nanocomposite film by combining hydrothermal and sol-gel spin coating assembly methods [18]. The film exhibited suitable optical contrast and fast switching time.
Furthermore, compared with LBL method, it is more convenient and can save a lot of time to prepare a device by sol-gel spin coating method.

\section{EXPERIMENTAL SECTION}

\subsection{Materials}

All the starting materials were reagent grade and used as purchased without further purification. $\mathrm{K}_{6} \mathrm{P}_{2} \mathrm{~W}_{18} \mathrm{O}_{62} \cdot \mathrm{nH}_{2} \mathrm{O} \quad\left(\mathrm{P}_{2} \mathrm{~W}_{18}\right)$ and $\mathrm{K}_{10} \mathrm{P}_{2} \mathrm{~W}_{17} \mathrm{O}_{61} \cdot \mathrm{nH}_{2} \mathrm{O}\left(\mathrm{P}_{2} \mathrm{~W}_{17}\right)$ were synthesized according to the published procedures and identified by IR spectra, UV-vis absorption spectra and cyclic voltammetry (CV). Fluorine doped tin oxide (FTO) were purchased from Yingkou OPV Tech New Energy Co.,Ltd $\left(7-8 \Omega \cdot \mathrm{cm}^{-1}\right)$ [19,20]. The Spin Coater (KW-4A) was purchased from the Institute of Electronics, Chinese Academy of Sciences.

\subsection{Preparation of $\mathrm{TiO}_{2}$ nanowires}

$\mathrm{The} \mathrm{TiO}_{2}$ nanowires was prepared according to the literature procedures [21]. Firstly, the surface of FTO glasses was cleaned with a detergent solution, rinsed with deionized water and ethanol and finally dried in a nitrogen stream. The precursor solution was obtained by mixing Tetrabutyl titanate, $\mathrm{HCl}$ and deionized water in a 0.03:1:1 volume ratio. And the FTO substrate was putted vertically into a Teflon-lined stainlesssteel autoclave which the precursor solution was transferred into before. Then the autoclave was heated in an oven at $150{ }^{\circ} \mathrm{C}$ for 4 hours and quenching to room temperature under flowing water. The FTO samples was taken out and washed with deionized water, and then annealed in air at $450^{\circ} \mathrm{C}$ for $30 \mathrm{~min}$.

\subsection{Preparation of Sol-gel}

Firstly, 0.5_mL Tetrabutyl titanate and $8 \mathrm{~mL}$ anhydrous ethanol was mixed and stirred violently, $0.7 \mathrm{~mL} \mathrm{HAc}$ and $0.6 \mathrm{~mL} \mathrm{HCl}$ was added into the Tetrabutyl titanate solution. Then $0.07 \mathrm{~g} \mathrm{P}_{2} \mathrm{~W}_{17}$ was dissolved in $66 \%$ alcohol solvent and added into the above solution. The mixture was stirred violently for 30 minutes, and the right amount of $\mathrm{HCl}$ was added in drop by drop to make it transparent and the sol-gel was obtained. 


\subsection{Preparation of composite films}

The surface of the FTO substrate was cleaned in a $\mathrm{H}_{2} \mathrm{SO}_{4} / \mathrm{H}_{2} \mathrm{O}_{2}$ (volume ratio $7: 3$ ) bath for $20 \mathrm{~min}$. Then the samples were putted into a $\mathrm{H}_{2} \mathrm{O} / \mathrm{H}_{2} \mathrm{O}_{2} / \mathrm{NH}_{4} \mathrm{OH}$ (volume ratio1:1:1) bath for 30 min after rinsed with deionized water. Repeat the two steps 5-10 times. Finally, the inorganic and organic impurities of the FTO substrate were removed.

The composite film was prepared by the sol-gel spin-coating process. The above-mentioned coating sol-gel was deposited on the $\mathrm{TiO}_{2} \mathrm{NW}$ substrate using spin coating technique. The spin parameters, including spin speed and time, were separately set at $1500 \mathrm{r} / \mathrm{min}$ and $45 \mathrm{~s}$. Then the coated substrate was place in the oven and dried at $150_{-}^{\circ} \mathrm{C}$ for 5 minutes. This coating and drying cycle was repeated for 5 times and then the coated composite film was annealed in air at $450{ }^{\circ} \mathrm{C}$ for $30 \mathrm{~min}$. The $\mathrm{TiO}_{2} \mathrm{NW}-$ $\mathrm{P}_{2} \mathrm{~W}_{17}$ film thus obtained was named as NW- $\mathrm{P}_{2} \mathrm{~W}_{17}$. For comparison, the coated film onto FTO substrate was obtained by the same method and was designated as FTO- $\mathrm{P}_{2} \mathrm{~W}_{17}$.

\subsection{Characterization}

The surface morphology was performed using scanning electron microscopy (SEM, Hitachi SU8010). UV-vis absorption spectra were performed on a TU-1901 UV-vis spectrophotometer. The electrochemical experiments were performed on the $\mathrm{CHI}-660 \mathrm{E}$ electrochemical workstation (Shanghai Chenhua Instrument Factory, China). A threeelectrode system was used for electrochemical measurement. The films acted as working electrode, a Pt wire was used as the counter electrode, $\mathrm{Ag} / \mathrm{AgCl}\left(3 \_\mathrm{mol} / \mathrm{L} \mathrm{KCl}\right)$ as the reference electrode and $0.2 \mathrm{~mol} / \mathrm{L} \mathrm{HOAc-}$ NaAc buffer solution as the electrolyte. The characteristics of electrochromic processes were performed by combining the electrochemical workstation with the in situ UV-vis spectrophotometer.

\section{RESULTS AND DISCUSSION}

\subsection{Morphology and homogeneity analysis}

The scanning electron microscopy (SEM) was used to detect the morphology and homogeneity of the POM-based films. As it is clearly seen in Fig. 1a-b, the surface of FTO substrate was covered with randomly grown $\mathrm{TiO}_{2}$ nanowires. Fig. 1c-d give the top-view SEM image of FTO$\mathrm{P}_{2} \mathrm{~W}_{17}$, the image indicates that the surface of FTO- $\mathrm{P}_{2} \mathrm{~W}_{17}$ film was covered with the aggregation of $\mathrm{P}_{2} \mathrm{~W}_{17}$ anions. The thickness of the FTO- $\mathrm{P}_{2} \mathrm{~W}_{17}$ film is approximately $60 \mathrm{~nm}$. As shown in Figure 1e-f, the nanowires became wider and more compact, which are evidences that the nanowires were wrapped by the sol-gel coating solutions. The thickness of the NW- $\mathrm{P}_{2} \mathrm{~W}_{17}$ film is approximately $600 \mathrm{~nm}$. And the interspace of nanowires was filled up, which was benefit for the surface smooth and it can be a reason for the improving of the stability of the composite films.

\subsection{Electrochemical behavior of the nanocomposite film}

Spectroelectrochemistry was used to assess the electrochemical performance of the composite films, and the FTO$\mathrm{P}_{2} \mathrm{~W}_{17}$ film was investigated for comparison. Figure 2 displays the visible spectra of $\mathrm{NW}-\mathrm{P}_{2} \mathrm{~W}_{17}$ and $\mathrm{FTO}-\mathrm{P}_{2} \mathrm{~W}_{17}$ films at colored and bleached state. As shown in Figure 3a-b, the film was colorless and transparent without any applied potential. And when the electrode was cathodically polarized, the films were colored to blue, which was caused by the optical absorption of an intervalence charge transfer band $\left(\mathrm{W}^{\mathrm{v}}-\mathrm{O}-\mathrm{W}^{\mathrm{vI}}\right.$ or $\left.\mathrm{W}^{\mathrm{v}}-\mathrm{O}-\mathrm{W}^{\mathrm{V}}\right)$. The films were bleached when applied a positive potential. The gradually coloration and bleaching of FTO$\mathrm{P}_{2} \mathrm{~W}_{17}$ is primarily due to the reduction and oxidation of $\mathrm{P}_{2} \mathrm{~W}_{17}$ anions. Optical contrast and response time are important parameters to evaluate an electrochromic material $[18,22]$. As shown in Figure 2a-b, the NW- $\mathrm{P}_{2} \mathrm{~W}_{17}$ film illustrates a higher and broader absorbance than FTO- $\mathrm{P}_{2} \mathrm{~W}_{17}$, which indicates that the optical contrast of NW- $\mathrm{P}_{2} \mathrm{~W}_{17}$ composite film is obviously better because of the incorporation of nanowires.
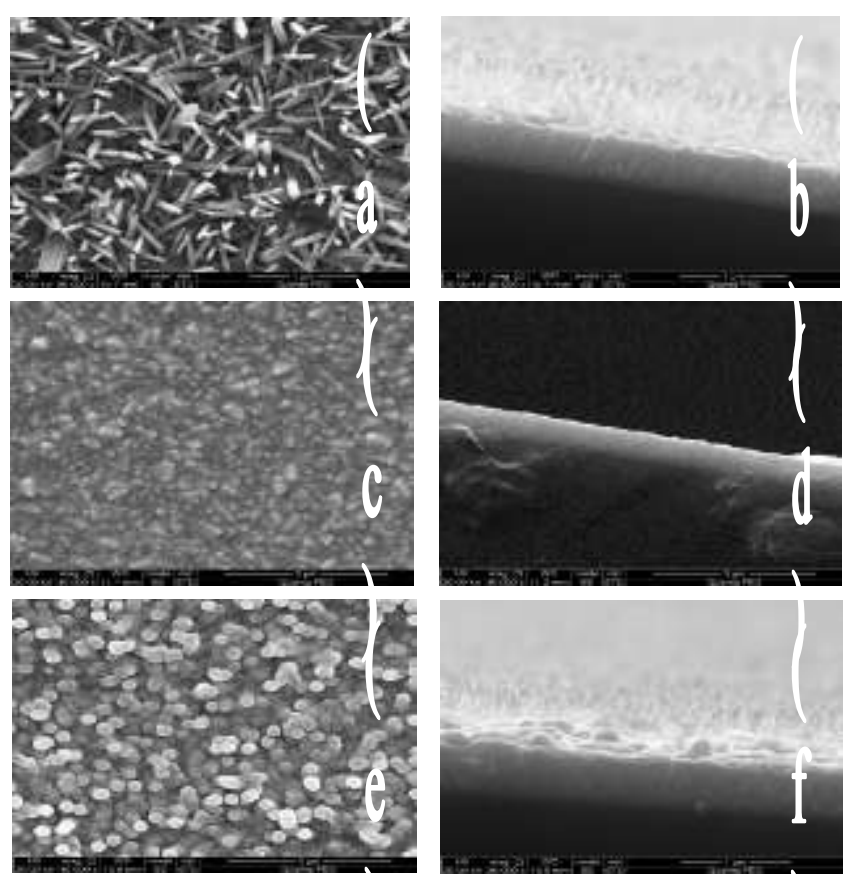

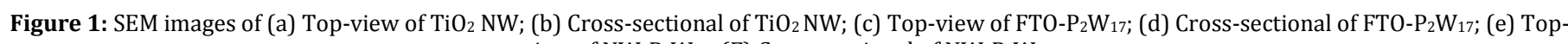
view of NW- $\mathrm{P}_{2} \mathrm{~W}_{17} ;$ (F) Cross-sectional of NW- $\mathrm{P}_{2} \mathrm{~W}_{17}$.

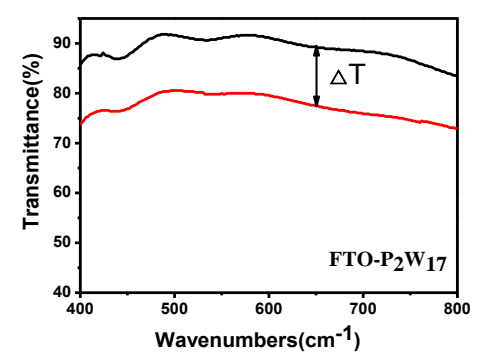

(a)

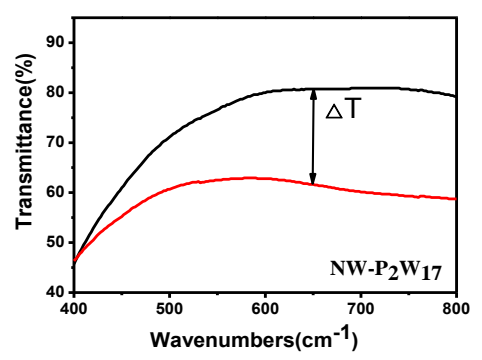

(b)

Figure 2: Visible Spectra of (a) FTO- $\mathrm{P}_{2} \mathrm{~W}_{17}$ and (b) NW- $\mathrm{P}_{2} \mathrm{~W}_{17}$ films at colored and bleached state. 
In this paper, the switching time between coloration and bleaching state is defined as the requirement for $90 \%$ of the total absorbance change to be reached at $650 \mathrm{~nm}$. The $\mathrm{NW}-\mathrm{P}_{2} \mathrm{~W}_{17}$ composite film shows a higher transient current density than the FTO- $\mathrm{P}_{2} \mathrm{~W}_{17}$ film, which is exhibited in Figure 3a. And Figure $3 \mathrm{~b}$ gives the corresponding in situ optical transmittance curves for NW- $\mathrm{P}_{2} \mathrm{~W}_{17}$ and $\mathrm{FTO}-\mathrm{P}_{2} \mathrm{~W}_{17}$ films at 650_nm during the subsequent

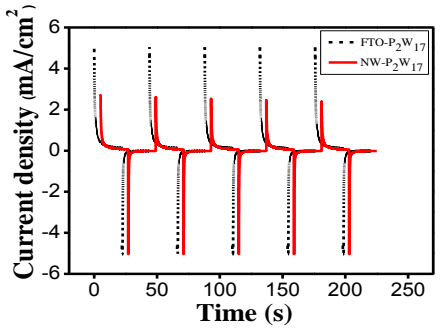

(a) double-potential steps chronoamperometric experiments at $+2 \mathrm{~V}$ to $-2 \mathrm{~V}$ The NW- $\mathrm{P}_{2} \mathrm{~W}_{17}$ composite film exhibits a optical contrast for $15.69 \%$ which is obviously higher than FTO- $\mathrm{P}_{2} \mathrm{~W}_{17}(11.07 \%)$. And the NW- $\mathrm{P}_{2} \mathrm{~W}_{17}$ film shows faster coloration and bleaching times of $0.82 \_\mathrm{s}$ and $2.98 \mathrm{~s}$, whereas the FTO- $\mathrm{P}_{2} \mathrm{~W}_{17}$ film needs $2.79 \mathrm{~s}$ and $3.39 \mathrm{~s}$.

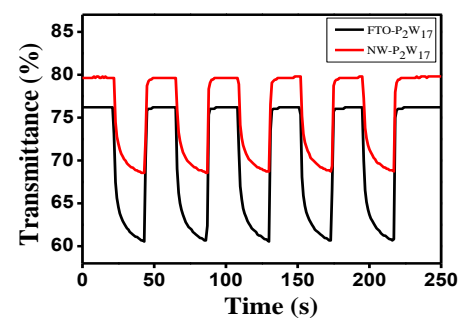

(b)

Figure 3: (a) Chronoamperometry Measurements and (b) Corresponding in situ optical transmittance curves for NW- $\mathrm{P}_{2} \mathrm{~W}_{17}$ and FT0- $\mathrm{P}_{2} \mathrm{~W}_{17}$ films at $650 \mathrm{~nm}$ during the subsequent double-potential step at $+2 \mathrm{~V}$ to $-2 \mathrm{~V}$ chronoamperometric experiments.

\section{CONCLUSION}

In summary, we synthesized a new nanocomposite film assembled by $\mathrm{P}_{2} \mathrm{~W}_{17}$ and the FTO substrate pre-coated with $\mathrm{TiO}_{2}$ nanowires by Sol-gel spin coating method. The composite film displayed enhanced electrochromic performance such as higher optical contrast $(15.69 \%$ at $650 \mathrm{~nm}$ ) and faster switching time (coloration and bleaching times of 2.98 $\mathrm{s}$ and $0.82 \mathrm{~s}$ ) than the single $\mathrm{P}_{2} \mathrm{~W}_{17}$ film. The improved electrochromic properties are obviously due to the incorporation of nanowires into the composite film, not only because of the $\mathrm{TiO}_{2}$ materials have EC properties but also the incorporation of nanowires could enhance the adsorption capacity and stability of the $\mathrm{P}_{2} \mathrm{~W}_{17}$ on FTO substrate. The result provided a reference for researching EC materials based on POMs and gave us a new route to promote the application for POMs-based EC devices.

\section{ACKNOWLEDGMENTS}

This work was supported by the Natural Science Foundation of China (Grant No. 21301041), Jilin Science and Technology Bureau (No. 201750215), Jilin Institute of Chemical Technology (No. 2015031).

\section{REFERENCES}

[1] Vuong, N.M., Kim, D., Kim, H. 2013. Electrochromic properties of porous $\mathrm{WO}_{3}-\mathrm{TiO}_{2}$ core-shell nanowires [J]. Journal of Materials Chemistry C, 1 (21), 3399-3407.

[2] Lv, X.J., Sun, J.W., Wang, P.J. 2014. A core-shell composite of porous ZnO nanosheets and a multichromic conducting polymer: enhanced electrochromic performances [J]. New Journal of Chemistry, 38 (6), 24002406.

[3] Pope, M.T., Müller, A. 1994. Polyoxometalates: From platonic solids to anti-retroviral activity $[\mathrm{M}]$. Springer Netherlands.

[4] Rhule, J.T., Hill, C.L., Judd, D.A. 1998. Polyoxometalates in Medicine [J]. Chemical Reviews, 98 (1), 327.

[5] Zhang, T.R., Feng, W., Fu, Y.Q. 2002. Self-assembled organic-inorganic composite superlattice thin films incorporating photo- and electrochemically active phosphomolybdate anion [J]. Journal of Materials Chemistry, 12 (5), 1453-1458.

[6] Liu, S.P., Xu, L., Li, F.Y. 2011. Enhanced electrochromic performance of composite films by combination of polyoxometalate with poly(3,4ethylenedioxythiophene) [J]. Journal of Materials Chemistry, 21 (6), 19461952.

[7] Liu, S.P., Xu, L., Gao, G.G. 2009. Multicolor electrochromic ultrathin films based on neutral red and polyoxometalate [J]. Thin Solid Films, 517 (16), 4668-4672.

[8] Gao, G., Xu, L., Wang. W.J. 2005. Electrochromic multilayer films based on trilacunary Dawson-type polyoxometalate [J]. Electrochimica Acta, 50 (5), 1101-1106.

[9] Li, N., Zhang, W.J., Hong, Y. 2013. An electrochromic composite film of Preyssler-type phosphotungstate decorated by AuNPs [J]. Journal of
Colloid \& Interface Science, 403 (4), 91-98.

[10] Heravi, M.M., Motamedi, R., Seifi, N. 2006. Catalytic synthesis of 6-aryl$1 \mathrm{H}$-pyrazolo[3,4-d]pyrimidin-4[5H]-ones by heteropolyacid: $\mathrm{H}_{14}$ $\left[\mathrm{NaP}_{5} \mathrm{~W}_{30} \mathrm{O}_{110}\right]$ and $\mathrm{H}_{3} \mathrm{PW}_{12} \mathrm{O}_{40}$ [J]. Journal of Molecular Catalysis A Chemical, 249 (1), 1-3.

[11] Gao, G.G., Xu, L., Wang, W.J. 2004. Electrochromic ultra-thin films based on cerium polyoxometalate [J]. Journal of Materials Chemistry, 14 (13), 2024-2029.

[12] Seelandt, B., Wark, M. 2012. Electrodeposited prussian blue in mesoporous $\mathrm{TiO}_{2}$ as electrochromic hybrid material []]. Microporous \& Mesoporous Materials, 164 (4), 67-70.

[13] Palneedi, H., Park, J.H., Maurya, D. 2018. Laser irradiation of metal oxide films and nanostructures: Applications and advances [J]. Advanced Materials, 1705148

[14] Reyes, K.R., Stephens, Z.D. 2013. Composite $\mathrm{WO}_{3} / \mathrm{TiO}_{2}$ nanostructures for high electrochromic activity [J]. Acs Appl Mater Interfaces, 7 (4), 2202 [15] Liu, S.P., Qu, X.S. 2017. Construction of nanocomposite film of Dawson-type polyoxometalate and $\mathrm{TiO}_{2}$, nanowires for electrochromic applications [J]. Applied Surface Science, 412, 189-195.

[16] Liu, S.Q., Tang, Z.Y. 2010. Polyoxometalate-based functional nanostructured films: Current progress and future prospects [J] . Nano Today, $5(4), 267-281$.

[17] Kuhn, A., Anson, F.C. 1996. Adsorption of monolayers of $\mathrm{P}_{2} \mathrm{Mo}_{18} \mathrm{O}_{62}{ }^{6-}$ and deposition of multiple layers of $\mathrm{Os}(\mathrm{bpy})^{32+} \mathrm{P}_{2} \mathrm{Mo}_{18} \mathrm{O}_{62} 2^{6-}$ on electrode surfaces [J]. Langmuir, 12 (22), 5481-5488.

[18] Wang, S.M., Liu, L., Chen, W.L. 2013. High performance visible and near-infrared region electrochromic smart windows based on the different structures of polyoxometalates [J]. Electrochimica Acta, 113 (4), 240-247.

[19] Haraguchi, N., Okaue, Y., Isobe, T. 1994. Stabilization of tetravalent cerium upon coordination of unsaturated heteropolytungstate anions [J]. Inorganic Chemistry, 33 (6), 240-241.

[20] Finke, R.G., Droege, M.W., Domaille, P.J. 1987. Trivacant heteropolytungstate derivatives. 3. Rational syntheses, characterization, two-dimensional tungsten-183 NMR, and properties of tungstometallophosphates $\mathrm{P}_{2} \mathrm{~W}_{18} \mathrm{M}_{4}\left(\mathrm{H}_{2} \mathrm{O}\right)_{2} \mathrm{O}_{68}{ }^{10}$ and $\mathrm{P}_{4} \mathrm{~W}_{30} \mathrm{M}_{4}\left(\mathrm{H}_{2} \mathrm{O}\right)_{2} \mathrm{O}_{112}{ }^{16-}$ ( $M$ = cobalt, copper, zinc) [J] . Inorganic Chemistry, 26 (23), 3886-3896.

[21] Sun, P., Zhang, X.T., Liu, X.P. 2012. Growth of single-crystalline rutile $\mathrm{TiO}_{2}$ nanowire array on titanate nanosheet film for dye-sensitized solar cells [J]. Journal of Materials Chemistry, 22 (13), 6389-6393.

[22] Wang, S.M., Liu, L., Chen, W.L. 2013. A new electrodeposition approach for preparing polyoxometalates-based electrochromic smart windows [J]. Journal of Materials Chemistry A, 1 (2), 216-220. 